\title{
Articles
}

\section{$\alpha$-Thalassaemia trait and gestational diabetes mellitus in Hong Kong}

\author{
T. T.Lao, L.F.Ho \\ Department of Obstetrics and Gynaecology, The University of Hong Kong and Tsan Yuk Hospital, Hong Kong SAR, China
}

\section{Abstract}

Aims/hypothesis. The purpose of this study was to examine the association between maternal $\alpha$-thalassaemia trait and the occurrence of gestational diabetes mellitus in at-risk Chinese women in Hong Kong. Methods. From 3320 pregnant women who had delivered in our hospital and undergone the oral glucose tolerance test for various risk factors over a threeyear period, 163 with $\alpha$-thalassaemia trait were identified (study group). The control group consisted of 163 women chosen from the next patient that was matched for maternal age and parity, following each index case. Comparison was made in the incidence of gestational diabetes mellitus defined by the World Health Organisation criteria, obstetric complications, and perinatal outcome.

Results. The incidence of gestational diabetes mellitus was higher in the study group $(62.0 \%$ vs $14.7 \%$, $p<0.0001$ ) which had a higher pre-pregnancy body mass index and lower haemoglobin concentrations. Although more patients in the study group had risk factors $(41.7 \%$ vs $26.4 \%, p=0.003)$, there was no difference in the pregnancy outcome or perinatal complications. Among the gestational diabetic women, those with $\alpha$-thalassaemia trait were considerably younger and their infants had lower body mass index but there was no significant difference in the outcome. On multiple logistic regression analysis, the $\alpha$ thalassaemia trait remained an important factor in the diagnosis of gestational diabetes (OR 11.74, $95 \%$ CI 6.37-21.63).

Conclusion/interpretation. Among women at risk of gestational diabetes, the presence of the $\alpha$-thalassaemia trait is an additional risk factor for gestational diabetes mellitus. [Diabetologia (2001) 44: 966-971]

Keywords Gestational diabetes mellitus, $\alpha$-thalassaemia trait, pregnancy outcome.
It is well documented that the health of subjects with $\beta$-thalassaemia major or intermedia is complicated by an increased risk of diabetes mellitus and other endocrine disorders [1-7]. This is consequent to haemosiderosis, which is due to repeated blood transfusion and chronic haemolysis. However, little is known

Received: 31 October 2000 and in revised form: 5 April 2001

Corresponding author: Dr. Terence Lao, Department of Obstetrics \& Gynaecology, Tsan Yuk Hospital, 30 Hospital Road, Hong Kong SAR, China

Abbreviations: GDM, gestational diabetes mellitus; MCV, mean cell volume; WHO, World Health Organisation; LGA, large-for-gestational age; OR odds ratio about the risk of diabetes mellitus, whether as a complication of treatment or of the underlying condition, in subjects with $\alpha$-thalassaemia.

Alpha-thalassaemia is absent or rare in Europe and Northern Asia and China [8, 9]. In Southern China and Southeast Asia, the $\alpha$-thalassaemia trait, haemoglobin $\mathrm{H}$ disease, and $\alpha$ - thalassaemia hydrops fetalis are found [8]. The incidence of the $\alpha$-thalassaemia trait is about $6 \%$ around Hong Kong [10,11], and up to $15 \%$ in Southern China [9]. A recent study [12] confirmed that $5 \%$ of the Chinese population in Hong Kong carry the $\alpha$-thalassaemia trait. The overwhelming majority $(4.5 \%)$ are carriers of the Southeast Asian type of deletion, in which both $\alpha$-globin genes on the same chromosome 16 are deleted $(\alpha-1$ 
thalassaemia), while $\alpha^{3,7}$ and $\alpha^{4,2}$ deletion were found in $0.3 \%$ and $0.2 \%$ respectively. As the perinatal mortality of infants with homozygous $\alpha-1 / \alpha-1$ thalassaemia (haemoglobin Bart's hydrops fetalis syndrome) is $100 \%[8,12,13]$, pregnancy was often discouraged in couples of which both were carriers of the $\alpha$-thalassaemia trait in the past. With the advent of prenatal diagnosis, it is now possible to confirm or exclude homozygous $\alpha$-thalassaemia in the fetus [14]. Thus more women with $\alpha$-thalassaemia trait can continue with their pregnancies, and this has probably accounted for the increase in the incidence of the $\alpha$-thalassaemia trait in our parturients from $1.7 \%$ in 1988 to $3.2 \%$ in 1998 (data from our annual statistics).

In a study on the relation between maternal anaemia and pregnancy outcome in Hong Kong, it was found that the incidence of gestational diabetes mellitus (GDM) was double among women with anaemia due to the thalassaemia trait compared to women with anaemia due to iron deficiency [15]. Although the majority of the women with the thalassaemia trait had the $\alpha$-thalassaemia trait, the increasing incidence of this group of parturients could not explain the significantly higher prevalence of GDM compared with parturients with iron deficiency anaemia in our population, unless the $\alpha$-thalassaemia trait could be a predisposing factor to GDM. In view of a recent case report of Type I (insulin-dependent) diabetes mellitus in a 37-year-old man with haemoglobin $\mathrm{H}$ disease [16], we suspect that the presence of $\alpha$-thalassaemia trait could be associated with the development of GDM. In order to examine this hypothesis, we have carried out a retrospective case-control study over a 3 -year period on the obstetric patients at risk of developing GDM who delivered in our hospital.

\section{Subjects and methods}

Our hospital is a regional hospital that caters to public patients only, with about 5000 deliveries a year and the majority of our patients ( $>95 \%$ ) are ethnic Chinese. In Hong Kong, the standard practice is to routinely check the haemoglobin ( $\mathrm{Hb})$ concentration, mean corpuscular volume (MCV) and blood group of patients routinely at their first antenatal visit. The MCV screening is done to identify mothers at risk of carrying the thalassaemia traits [12]. Those with a MCV of less than $80 \mathrm{fl}$ will be investigated further with $\mathrm{Hb}$ electrophoresis and examination of the blood smear for Haemoglobin-H inclusion bodies, and iron status (serum ferritin measurement) will be determined if the $\mathrm{Hb}$ concentration is less than $10 \mathrm{~g} / \mathrm{dl}$. The partner also undergoes the MCV screening. If both partners have low MCV, prenatal diagnosis is done to determine if the fetus is affected by homozygous $\alpha$-thalassaemia, for which termination of pregnancy would be offered. The diagnosis of $\alpha$-thalassaemia trait is based on the finding of normal or decreased percentage of haemoglobin $\mathrm{A}_{2}$ and the presence of Haemoglobin-H inclusion bodies. Conducting studies on the genotype of $\alpha$-thalassaemia carriers is not a routine procedure of the clinical service, since it is known from previous studies that the great majority of the carriers have the $\alpha-1$ thalassaemia trait.
A multivitamin preparation containing $29 \mathrm{mg}$ of elemental iron is prescribed to all patients from 20 weeks of gestation. Folic acid $5 \mathrm{mg}$ daily is prescribed to women diagnosed to have the $\alpha$-thalassaemia trait irrespective of their $\mathrm{Hb}$ content, but iron therapy is not given unless concomitant iron deficiency, which is very uncommon in this group of women, is diagnosed at the initial screening. Otherwise the pregnancy is managed in a manner similar to that for the non-anaemic women. At 28 to 30 weeks $\mathrm{Hb}$ is estimated again to identify mothers who might have developed anaemia and further therapy will be given as necessary. Blood transfusion however is not given before delivery unless the $\mathrm{Hb}$ is less than $8 \mathrm{~g} / \mathrm{dl}$ and the women are symptomatic but blood will be cross-matched and reserved during labour and delivery for transfusion where indicated.

Our hospital adopts a universal screening programme for GDM by means of risk factors and random glucose at the third trimester. Women with risk factors for developing GDM, such as advanced maternal age ( $>35$ years), relevant past obstetric and family history, pre-pregnant weight of $75 \mathrm{~kg}$ or more, and recurrent and/or significant glycosuria, or other findings such as polyhydramnios or excessive fetal growth during the index pregnancy, take the $75 \mathrm{~g}$ OGTT and the result is interpreted by the World Health Organisation criteria [17]. In addition, all women at low risk and those with previous normal OGTT have blood drawn for random blood glucose testing at the beginning of the third trimester (28-30 weeks). A positive screen refers to a glucose concentration of more than $5.8 \mathrm{mmol} / \mathrm{l}$ if less than $2 \mathrm{~h}$ postprandial, and more than $5.0 \mathrm{mmol} / \mathrm{l}$ if more than $2 \mathrm{~h}$ postprandial; these patients also undergo the $75 \mathrm{~g}$ OGTT. Women diagnosed to have GDM are referred to a dietitian and their diet controlled $(30 \mathrm{kcal} / \mathrm{kg})$. Then they are assessed with a 2 -h postprandial blood sugar profile. Insulin therapy is given for inadequate control (postprandial glucose $>7 \mathrm{mmol} / \mathrm{l}$ ) if dietary readjustment failed to normalize the blood sugar profile. The diagnosis and management of GDM in our population has been described [18].

From a database on women who had undergone the OGTT from 1994 to 1996, women who were carriers of the $\alpha$-thalassaemia trait and delivered in our hospital were identified. From amongst the other women without haemoglobinopathies, those closest to each index case and matched for exact age and parity, and ethnicity, were selected as controls in order to minimise the effect of confounding factors in maternal demographics. We matched for parity because parity affects pregnancy outcome and is an important risk factor for GDM in Asian women [19]. We have not matched for other risk factors such as family history or obesity because of the relatively low incidence of these factors. Maternal demographics, OGTT and $\mathrm{Hb}$ results, pregnancy complications and infant outcome were compared between the groups with and without the $\alpha$ thalassaemia trait. The pregnancy complications we examined included caesarean section [20-22], pre-eclampsia [20-22], antepartum haemorrhage [22], and preterm birth [21]. For infant outcome, large-for-gestational age (LGA) is defined as birthweight above the 90th percentile for gestational age in our local population according to our standardised chart. Statistical analysis was done with the Student's $t$ test, chi square or Fisher's exact test depending on the size of each cell and the odds ratio was calculated where indicated, using a commercial statistical package (Statistical Package for Social Sciences).

\section{Results}

During the study, there were 14450 deliveries and the overall incidence of GDM was $12.1 \%$. Of the 3320 
Table 1. Maternal and infant demographic data in study and control groups

\begin{tabular}{|c|c|c|c|}
\hline & Study group $(n=163)$ & Control group $(n=163)$ & Difference \\
\hline Age (years) & $30.8 \pm 4.5$ & $30.8 \pm 4.5$ & NS \\
\hline $\begin{array}{l}\text { Weight }(\mathrm{kg}) \\
\text { booking } \\
\text { pre-delivery }\end{array}$ & $\begin{array}{l}53.9 \pm 8.6 \\
65.6 \pm 8.7\end{array}$ & $\begin{array}{l}52.6 \pm 7.3 \\
65.1 \pm 7.9\end{array}$ & $\begin{array}{l}\text { NS } \\
\text { NS }\end{array}$ \\
\hline Height $(\mathrm{cm})$ & $154.7 \pm 5.7$ & $155.4 \pm 5.5$ & NS \\
\hline $\begin{array}{l}\mathrm{BMI}\left(\mathrm{kg} / \mathrm{M}^{2}\right) \\
\text { booking } \\
\text { pre-delivery }\end{array}$ & $\begin{array}{l}22.6 \pm 3.4 \\
27.4 \pm 3.3\end{array}$ & $\begin{array}{l}21.8 \pm 3.1 \\
27.0 \pm 3.2\end{array}$ & $\begin{array}{l}p=0.038 \\
\text { NS }\end{array}$ \\
\hline $\begin{array}{l}\mathrm{Hb}(\mathrm{g} / \mathrm{dl}) \\
\text { booking } \\
\text { third trimester }\end{array}$ & $\begin{array}{l}11.2 \pm 1.1 \\
10.7 \pm 1.0\end{array}$ & $\begin{array}{l}12.4 \pm 1.0 \\
11.7 \pm 0.9\end{array}$ & $\begin{array}{l}p=0.000 \\
p=0.000\end{array}$ \\
\hline $\begin{array}{l}\text { OGTT }(\mathrm{mmol} / \mathrm{l}) \\
0-\mathrm{h} \\
2-\mathrm{h}\end{array}$ & $\begin{array}{l}4.6 \pm 0.5 \\
8.0 \pm 1.7\end{array}$ & $\begin{array}{l}4.4 \pm 0.4 \\
6.7 \pm 1.3\end{array}$ & $\begin{array}{l}p=0.014 \\
p=0.000\end{array}$ \\
\hline Gestation (weeks) & $38.9 \pm 1.5$ & $39.0 \pm 1.6$ & NS \\
\hline Birthweight (g) & $3190 \pm 497$ & $3198 \pm 422$ & NS \\
\hline Crown Heel Length $(\mathrm{cm})$ & $50.0 \pm 2.1$ & $50.3 \pm 2.1$ & NS \\
\hline $\begin{array}{l}\text { Apgar Score at } 1 \mathrm{~min} \\
5 \mathrm{~min}\end{array}$ & $\begin{array}{l}8.8 \pm 1.2 \\
9.8 \pm 05\end{array}$ & $\begin{array}{l}8.6 \pm 1.3 \\
9.8 \pm 0.5\end{array}$ & $\begin{array}{l}\text { NS } \\
\text { NS }\end{array}$ \\
\hline
\end{tabular}

Comparison with the Student's $t$ test or * chi square test as indicated

Table 2. Risk factors for GDM in the study and control groups

\begin{tabular}{lcll}
\hline & $\begin{array}{l}\text { Study } \\
\text { group } \\
(n=163)\end{array}$ & $\begin{array}{l}\text { Control } \\
\text { group } \\
(n=163)\end{array}$ & $\begin{array}{l}\text { chi } \\
\text { square } \\
\text { test }\end{array}$ \\
\hline Presence of risk factors & $67(41.1)$ & $43(26.4)$ & $p=0.003$ \\
Family history & $23(14.1)$ & $16(9.8)$ & NS \\
Advanced age & $34(20.9)$ & $34(20.9)$ & NS \\
Past history & $10(6.1)$ & $4(2.5)$ & NS \\
Obesity & $4(8.6)$ & $1(6.1)$ & NS \\
Glycosuria & $5(3.1)$ & $1(0.6)$ & NS \\
Other & $3(1.8)$ & $2(1.3)$ & NS \\
Combination & $1(0.6)$ & 0 & NS
\end{tabular}

Results expressed in number (\% of whole group)

patients in the database, $\alpha$-thalassaemia trait was diagnosed in 163 Chinese patients (4.9\%). The mean maternal age was $30.8 \pm 4.5$ years, and the incidence of nulliparous women was $49.7 \%(81 / 163)$. There was no difference in the maternal pre-pregnancy or pre-delivery weight, height, or pre-delivery BMI between the study and control groups, but pre-pregnancy BMI was significantly higher in the study group (Table 1). As expected, the $\mathrm{Hb}$ concentrations at booking and the third trimester were higher in the control group but the results of the OGTT were higher in the study group. This was due to the fact that $62.0 \%$ of the study group had glucose intolerance, in contrast to the $14.7 \%$ in the control group $(p=0.000$, OR $9.44,95 \%$ CI 5.52-16.13). The inci-
Table 3. Pregnancy complications and outcome in study and control groups

\begin{tabular}{|c|c|c|c|}
\hline & $\begin{array}{l}\text { Study } \\
\text { group } \\
(n=163)\end{array}$ & $\begin{array}{l}\text { Control } \\
\text { group } \\
(n=163)\end{array}$ & $\begin{array}{l}\text { chi } \\
\text { square } \\
\text { test }\end{array}$ \\
\hline Preterm labour & 3.7 & 3.1 & NS \\
\hline $\begin{array}{c}\text { Prelabour rupture } \\
\text { of membranes }\end{array}$ & 16.0 & 14.7 & NS \\
\hline $\begin{array}{l}\text { Antepartum haemor- } \\
\text { rhage }\end{array}$ & 12.3 & 5.5 & $p=0.031$ \\
\hline Pre-eclampsia & 5.5 & 4.3 & NS \\
\hline Induced labour & 16.0 & 18.4 & NS \\
\hline $\begin{array}{l}\text { Delivery before onset } \\
\text { of labour }\end{array}$ & 7.4 & 6.7 & NS \\
\hline Instrumental delivery & 21.6 & 23.9 & NS \\
\hline Caesarean section & 16.0 & 17.8 & NS \\
\hline
\end{tabular}

Results expressed in \%

dence of GDM in the non-thalassaemic group was $21.9 \%$. While all the patients with glucose intolerance in the control group belonged to the WHO category of impaired glucose tolerance (IGT), 3.1\% in the study group had diabetes mellitus, and the ratio of IGT to diabetes mellitus was 19:1. However, there was no difference in the gestatrional age, the size of the newborn, or Apgar scores. All the patients with gestational diabetes mellitus in the study and control groups were managed successfully with diet treatment. 
Table 4. Perinatal outcome in study and controls groups

\begin{tabular}{lccl}
\hline & $\begin{array}{l}\text { Study } \\
\text { group } \\
(n=163)\end{array}$ & $\begin{array}{l}\text { Control } \\
\text { group } \\
(n=163)\end{array}$ & $\begin{array}{l}\text { chi } \\
\text { square } \\
\text { test }\end{array}$ \\
\hline Macrosomia $(\geq 4000 \mathrm{~g})$ & 4.3 & 3.1 & $\mathrm{NS}$ \\
$\begin{array}{l}\text { Large-for-gestational age } \\
\text { Apgar score }<7\end{array}$ & 13.6 & 11.7 & $\mathrm{NS}$ \\
$\quad \begin{array}{l}\text { min } \\
5 \text { min }\end{array}$ & 4.5 & 8.0 & $\mathrm{NS}$ \\
Phototherapy for jaundice & 0 & 0 & $\mathrm{NS}$ \\
Meconium aspiration syndrome & 0.6 & 0.6 & $\mathrm{NS}$ \\
Clinical sepsis & 4.3 & 4.9 & $\mathrm{NS}$ \\
Neurological complications & 0.6 & 0.6 & $\mathrm{NS}$ \\
Metabolic complications & 2.0 & 2.0 & $\mathrm{NS}$ \\
Birth trauma & 1.3 & 1.3 & $\mathrm{NS}$ \\
\hline
\end{tabular}

Results expressed in \%

The indications for OGTT were examined in Table 2. Risk factors were found to be present in $41.7 \%$ of the study group and $26.4 \%$ of the controls $(p=0.003$, OR $2.02,95 \%$ CI $1.27-3.22)$ and often more than one risk factor could be found with the same case. However, there was no difference in the pattern or distribution of the risk factors. Although the incidence of diabetes mellitus in the first-degree relatives was higher in the study group, the difference was not statistically significant. Despite the higher incidence of GDM in the study group, there was no difference in the incidence of the common obstetric complications except for a higher incidence of antepartum haemorrhage in the study group $(p=0.031$, OR 2.41, 95\% CI 1.06-5.47, Table 3). There was also no difference in the type of labour or the mode of delivery. Similarly, there was no difference in the perinatal outcome (Table 4).

The GDM pregnancies were further analysed according to the presence or absence of the maternal $\alpha$-thalassaemia trait. Except for a younger maternal age and a lower infant BMI in the study group, there was no difference in the maternal or newborn characteristics, or in the mean values of the antepartum and postnatal OGTT (Table 5). There was no difference in the incidence of the common obstetric and perinatal complications between these two groups (Table 6).

To determine the role of maternal $\alpha$-thalassaemia trait in the development of GDM, stepwise multiple logistic regression analysis was carried out. The risk factors analysed included high BMI $\left(>26 \mathrm{~kg} / \mathrm{m}^{2}\right)$ before pregnancy, advanced maternal age ( $\geq 35$ years), family history of diabetes in first degree relatives, past history of GDM, and the presence of $\alpha$-thalassaemia trait. The presence of $\alpha$-thalassaemia trait was the most significant factor (OR 11.74, 95\% CI 6.37-21.63), followed by past history of GDM (OR 9.57, 95\% CI 1.98-46.14), advanced maternal age (OR 5.29, 95 \% CI 2.56-10.93), and high pre-pregnancy BMI (OR 2.61, 95\% CI 1.08-6.32). Family history was excluded as a significant factor (OR 2.26, $95 \%$ CI 0.95-5.36).

Table 5. Comparison between GDM women with and without the $\alpha$-thalassaemia trait

\begin{tabular}{|c|c|c|c|}
\hline & With thalassaemia $(n=101)$ & Without thalassaemia $(n=24)$ & Difference \\
\hline Age (years) & $31.5 \pm 4.4$ & $34.5 \pm 4.7$ & $p=0.004$ \\
\hline $\begin{array}{l}\text { Weight }(\mathrm{kg}) \\
\text { booking } \\
\text { pre-delivery }\end{array}$ & $\begin{array}{l}55.0 \pm 9.5 \\
65.8 \pm 9.4\end{array}$ & $\begin{array}{l}54.8 \pm 7.0 \\
65.5 \pm 7.1\end{array}$ & $\begin{array}{l}\text { NS } \\
\text { NS }\end{array}$ \\
\hline Height $(\mathrm{cm})$ & $154.8 \pm 5.5$ & $153.9 \pm 4.1$ & NS \\
\hline $\begin{array}{l}\mathrm{BMI}\left(\mathrm{kg} / \mathrm{M}^{2}\right) \\
\text { booking } \\
\text { pre-delivery }\end{array}$ & $\begin{array}{l}23.0 \pm 3.8 \\
27.5 \pm 3.6\end{array}$ & $\begin{array}{l}23.2 \pm 3.3 \\
27.7 \pm 3.5\end{array}$ & $\begin{array}{l}\text { NS } \\
\text { NS }\end{array}$ \\
\hline $\begin{array}{l}\mathrm{Hb}(\mathrm{g} / \mathrm{dL}) \\
\text { booking } \\
\text { third trimester }\end{array}$ & $\begin{array}{l}11.3 \pm 1.1 \\
10.7 \pm 1.0\end{array}$ & $\begin{array}{l}12.5 \pm 0.9 \\
11.8 \pm 0.8\end{array}$ & $\begin{array}{l}p=0.000 \\
p=0.000\end{array}$ \\
\hline $\begin{array}{l}\text { OGTT }(\mathrm{mmol} / \mathrm{l}) \\
0 \mathrm{~h} \\
2 \mathrm{~h}\end{array}$ & $\begin{array}{l}4.6 \pm 0.5 \\
9.0 \pm 0.9\end{array}$ & $\begin{array}{l}4.6 \pm 0.5 \\
8.9 \pm 0.8\end{array}$ & $\begin{array}{l}\text { NS } \\
\text { NS }\end{array}$ \\
\hline $\begin{array}{l}\text { Postnatal OGTT } \\
0 \mathrm{~h} \\
2 \mathrm{~h}\end{array}$ & $\begin{array}{l}5.0 \pm 0.5 \\
6.3 \pm 1.7\end{array}$ & $\begin{array}{l}5.0 \pm 0.3 \\
6.0 \pm 1.3\end{array}$ & $\begin{array}{l}\text { NS } \\
\text { NS }\end{array}$ \\
\hline
\end{tabular}

Comparison with the Student's $t$ test 
Table 6. Pregnancy outcome and postnatal glucose tolerance status in GDM women with and without the thalasaemia trait

\begin{tabular}{lccc}
\hline & With thalassaemia $(n=101)$ & Without thalassaemia $(n=24)$ & chi square test \\
\hline Nulliparous women & 49.5 & 41.7 & NS \\
Maternal age $\geq 35$ years & 25.7 & 50.0 & $p=0.020$ \\
Preterm labour & 3.0 & 0 & NS \\
Prelabour rupture of membranes & 15.0 & 8.3 & NS \\
Antepartum haemorrhage & 15.0 & 16.7 & NS \\
Group B Streptococcus carriage & 3.1 & 0 & NS \\
Pre-eclampsia & 8.9 & 8.3 & NS \\
Caesarean section & 17.0 & 20.8 & NS \\
Infant macrosomia & 5.0 & 8.3 & NS \\
Large for gestational age & 17.0 & 12.5 & NS \\
Phototherapy for jaundice & 16.7 & 29.2 & NS \\
Clinical sepsis & 5.0 & 4.2 & NS \\
Metabolic complications & 1.0 & 4.2 & NS \\
Postnatal OGTT & $80.2(81 / 101)$ & $70.8(17 / 24)$ & NS \\
$\quad$ Abnormal results & $18.5(15 / 81)$ & $17.6(3 / 17)$ & \\
IGT & $17.3(14 / 81)$ & 0 & \\
Diabetes mellitus & $1.2(1 / 81)$ & & \\
\hline
\end{tabular}

Results expressed in \% and compared with the chi square test

\section{Discussion}

In this study, the prevalence of GDM in women with $\alpha$-thalassemia trait was $62 \%$, a figure that was fourfold higher than the control subjects who were also at risk but without the $\alpha$-thalassaemia trait. It was possible that the higher prevalence of GDM in the women with the $\alpha$-thalassemia trait was related to risk factors such as age, parity, and maternal BMI, all of which have been shown to be higher in the women with GDM in our population [18]. While the pre-pregnancy BMI was higher in the study group, the difference was clinically small. In addition, although the overall incidence of risk factors was increased in the women with the $\alpha$-thalassaemia trait, there was no difference in the incidence of the individual factors or in the distribution of these factors. Multiple logistic regression analysis confirmed that the presence of $\alpha$-thalassaemia trait was the most significant risk factor.

The underlying cause of the association between $\alpha$-thalassaemia trait and GDM is not known. There is a relation between iron overload and the development of diabetes mellitus, such as in the patients with transfusion-treated $\beta$-thalassaemia major [1] and genetic haemochromatosis [23]. Increased iron store in the women with $\alpha$-thalassaemia trait could be a contributing factor. This is because the anaemia found in the pregnant women with $\alpha$-thalassemia trait is due to the defect in globin chain synthesis and their iron stores tend to be normal or high, dependent on actual iron utilisation [15]. However, a high serum ferritin concentration is usually associated with $\mathrm{Hb} \mathrm{H}$ disease and not with the $\alpha-1$ thalas- semia trait, and blood transfusion to maintain the $\mathrm{Hb}$ concentration is not necessary for these women. Also there is no known association between the $\alpha$ thalassaemia trait and haemochromatosis. Although maternal third trimester serum ferritin concentration has been shown to be significantly higher in nonanaemic non-thalassaemic women with IGT compared with non-diabetic control subjects [24], we had not measured maternal serum ferritin concentration at the time of the OGTT in the women with thalassaemia traits. The hypothesis that iron excess plays a role in the development of GDM in these women must therefore be speculative.

Iron excess might not be the only explanation of the high prevalence of GDM in women with $\alpha$-thalassemia trait, because pancreatic $\alpha$-cell overactivity with increased glucagon response has also been shown in thalassaemic patients with impaired glucose tolerance [25]. It is possible that there are other subtle metabolic disturbances associated with $\alpha$-thalassemia trait that could predispose a pregnant women to the development of GDM but the pathophysiological mechanism of GDM in women with $\alpha$-thalassemia trait remains to be elucidated.

Of note, there was no difference in the obstetric or perinatal outcome between the study and control groups, despite the difference in the prevalence of GDM. It was possible that as the great majority of women with GDM had the WHO category of IGT, diet treatment had normalised glycaemic control and hence pregnancy outcome. Nonetheless, the GDM pregnancies in the study group had a $17 \%$ incidence of LGA infants despite a lower infant BMI. It was also possible that the effect of GDM had cancelled 
out any unfavourable effect of the haemoglobinopathy on the pregnancy. A third possibility was that the abnormal OGTT was a reflection of the insulin resistance state in women with $\alpha$-thalassaemia trait rather than the diabetogenic effect of their pregnancies. Thus their pregnancy outcome might actually be better than that in GDM women without the thalassaemia trait. This might have explained the lower incidence of women aged 35 years or older, as well as the trend of lower incidence of infant macrosomia, phototherapy for jaundice, and metabolic complications, which failed to reach statistical significance because of the small numbers.

Our findings indicate that in Hong Kong, the incidence of $\alpha$-thalassaemia trait in women at risk of GDM $(4.9 \%)$ was similar to the $5 \%$ incidence of $\alpha$ thalassaemia trait in the overall population in our locality [12]. However, the presence of $\alpha$-thalassaemia trait significantly increases the likelihood of GDM. Although there is as yet no long-term follow-up studies on women with the $\alpha$-thalassaemia trait, they are probably also at increased risk for the later development of diabetes mellitus.

\section{References}

1. Saudek CD, Hemm RM, Peterson CM (1997) Abnormal glucose tolerance in $\beta$-thalassaemia. Metabolism 26: 43-52

2. Brianda S, Maioli M, Frulio T et al. (1987) The euglycemic clamp in patients with thalassaemia intermedia. Horm Metab Res 19: 319-322

3. De Sanctis V, Zurlo MG, Senesi E et al. (1988) Insulin dependent diabetes in thalassaemia. Arch Dis Child 63: 58-62

4. Merkel PA, Simonson DC, Amiel SA et al. (1988) Insulin resistance and hyperinsulinemia in patients with thalassemia major treated by hypertransfusion. N Engl J Med 318: 809-814

5. Dmochowski K, Finegood DT, Francombe W et al. (1993) Factors determining glucose tolerance in patients with thalassemia major. J Clin Endocrinol Metab 77: 478-483

6. Cavallo-Perin P, Pacini G, Cerutti F et al. (1995) Insulin resistance and hyperinsulinemia in homozygous $\beta$-thalassemia. Metabolism 44: 281-286

7. Italian Working Group on Endocrine Complications in Non-endocrine Diseases (1995) Multicentre study on prevalence of endocrine complications in thalassaemia major. Clin Endocrinol (Oxf) 42: 581-586

8. Stein J, Berg C, Jones JA, Detter JC (1984) A screening protocol for a prenatal population at risk for inherited hemoglobin disorders: results of its application to a group of
Southeast Asians and blacks. Am J Obstet Gynecol 150: 333-341

9. Angastiniotis M, Modell B, Englezos P et al. (1995) Prevention and control of haemoglobinopathies. Bull World Health Organ 73: 375-386

10. Tamagnini GP (1988) Congenital anaemias in Macau. Haemoglobin 12: 637-643

11. Li AMC, Cheng MY (1990) Anaemia and thalassaemia in healthy adolescents from southern Chinese families. J Paediatr Child Health 26: 339-342

12. Lau Y-L, Chan L-C, Chan Y-Y et al. (1997) Prevalence and genotypes of $\alpha$ - and $\beta$-thalassemia carriers in Hong Kong implications for population screening. N Engl J Med 336: 1298-1301

13. Liang ST, Wong VCW, So WWK, Ma HK, Chan V, Todd D (1985) Homozygous $\alpha$-thalassaemia: clinical presentation, diagnosis and management. A review of 46 cases. Br J Obstet Gynaecol 92: 680-684

14. Lam YH, Ghosh A, Tang MHY et al. (1997) The risk of $\alpha$ thalassaemia offspring of $\beta$-thalassaemia carriers in Hong Kong. Prenatal Diagnosis 17: 733-736

15. Lao TT, Pun TC (1996) Anaemia in pregnancy - is the current definition meaningful? Eur J Obstet Gynecol Reprod Biol 68: 53-58

16. Chim CS, Chan V, Todd D (1998) Hemosiderosis with diabetes mellitus in untransfused Hemoglobin $\mathrm{H}$ disease. Am J Hematol 57: 160-163

17. World Health Organization Expert Committee on Diabetes Mellitus (1980) Technical report series No 646, WHO, Geneva

18. Lao TT, Lee CP (1998) Gestational "impaired glucose tolerance": should the cut-off be raised to $9 \mathrm{mmoll}^{-1}$ ? Diabet Med 15: 25-29

19. Dornhorst A, Paterson CM, Nicholls JS et al. (1992) High prevalence of gestational diabetes in women from ethnic minority groups. Diabet Med 9: 820-825

20. Tan YY, Yeo GS (1996) Impaired glucose tolerance in pregnancy - is it of consequence? Aust N Z J Obstet Gynaecol 36: 248-255

21. El Mallah KO, Narchi H, Kulaylet NA, Shaban MS (1997) Gestational and pre-gestational diabetes: comparison of maternal and fetal characteristics and outcome. Int J Gynaecol Obstet 58: 203-209

22. McMahon MJ, Ananth CV, Liston RM (1998) Gestational diabetes mellitus. Risk factors, obstetric complications and infant outcomes. J Reprod Med 43: 372-378

23. Adams PC, Kertesz AE, Valberg LS (1991) Clinical presentation of hemochromatosis: a changing scene. Am J Med 90: 445-449

24. Lao TT, Tam KF (1997) Maternal serum ferritin and gestational impaired glucose tolerance. Diabetes Care 20: 1368-1369

25. Passariello N, Paolisso G, Sgambato S et al. (1987) Role of alpha and beta cells in the impaired glucose tolerance of thalassaemic subjects. Diabetes Metab 13: 436-440 